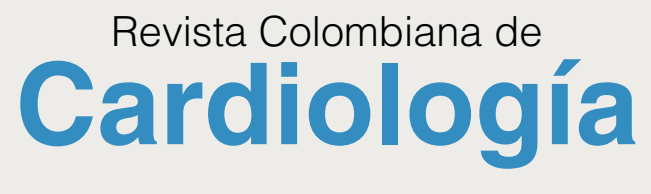

www.elsevier.es/revcolcar

EDITORIAL

\title{
Adults with congenital heart disease: a growing population. Challenges of the present and the future
}

\author{
Néstor Sandoval
}

Cardiovascular Surgery, Institute of Congenital Heart Diseases, Fundación Cardioinfantil-Instituto de Cardiologia, Bogota, Colombia

Received 3 May 2017; accepted 4 May 2017

Available online 31 May 2017

\section{Background}

The population of adults with congenital heart disease is increasing and is estimated to grow at a rate of $6 \%$ per year in developed countries. In the United States alone, it is estimated that there are approximately 1.4 million people suffering from this condition, compared to one million patients under 18 with congenital heart disease.

This can be explained by the availability of better and more timely diagnostic methods, especially in prenatal diagnosis with fetal echo, optimal surgical and interventional results, successful specialized cardiovascular intensive care and the experience of high-volume reference centers that provide comprehensive management with lower postoperative mortality, which leads to greater survival in the medium and long term. In general, with these measures, $85 \%$ of patients with congenital heart disease are expected to reach adulthood $^{1,2}$.

In the world life expectancy at birth has improved, and in Colombia today it is 73.95 years in the general population; 70.95 for men and 77.10 for women, a factor that favors adults with heart disease, since they are influenced by this general change ${ }^{3}$.

A study carried out in Quebec shows how in two different periods, one from 1987 to 1988 compared to the period between 2004 and 2005 there is a large change in the

DOI of original article:

http://dx.doi.org/10.1016/j.rccar.2017.05.001

E-mail address: nsandoval@cardioinfantil.org mortality of children with congenital heart disease. In the first period, mortality during the first year of life was $25 \%$, compared to the general population in which it was less than 1\%. Subsequently, in the second period studied from 2004 to 2005, this mortality decreased especially in the first year, and became very similar to that of the general population, a fact that supports the hypothesis of why this population reaches adulthood in a very high percentage ${ }^{4}$.

The Warnes et al. study reported how the possibility of survival to adulthood after surgery has changed since the 1950 s when it was only $25 \%$, to $90 \%$ by $2010^{5}$ (fig. 1 ).

\section{Severity of disease and causes of mortality}

Congenital heart diseases have different degrees of severity independently of the scale to determine surgical risk (RACHS-1 or STAT) ${ }^{6,7}$. Some authors classify them as simple, moderate and severe.

The simple ones include: simple interventricular communication, bicuspid aortic valve without lesion, simple mitral lesion, ductus arteriosus and mild pulmonary stenosis. This group corresponds to $47 \%$ of cardiopathies. The second or moderate group (which represents 38\%) includes heart diseases such as tetralogy of Fallot, complex defects of the interventricular septum, Partial anomalous venous drainage, partial AV canal, coartation of the aorta, Ebstein's anomaly and pulmonary stenosis, among others. The third group correspond to $15 \%$ and include severe defects some more serious such mitral atresia, transposition of great arteries, corrected transposition, heterotaxia syndromes, double outlet rigth or left ventricle truncus arteriosus, 


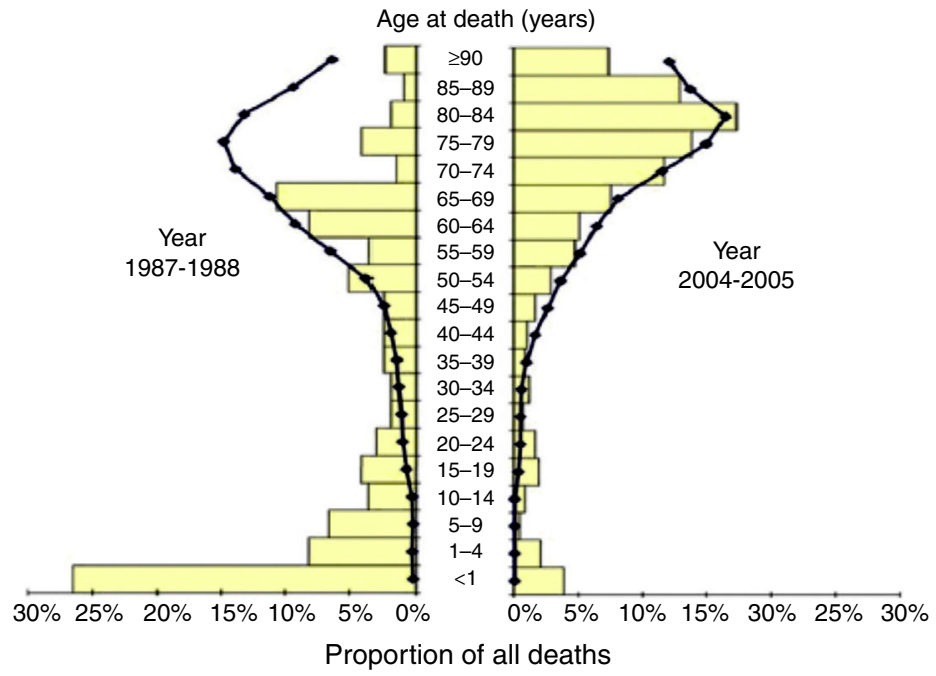

Figure 1 Distribution of age at Death in patients with Congenital heart diseases in 1987 to 1988 and 2004 to 2005. Source: Khairy et al.Changing mortality in congenital heart disease. JACC.2010;56:1149-57.

In this study two different periods from 1987 to 1988 compared to the period between 2004 and 2995, are shown, where the change in mortality risk is observed especially during the first year of life vs. the general population.

single ventricle and cyanotic lesions, as well as Eisenmenger syndrome ${ }^{8,9}$.

The most important of this classification is that it includes the prognostic dimension. $50 \%$ of the patients in the moderate and severe groups will require a reoperation and a large number will have other complications such arrhytmias of dificult management, heart failure, pulmonary hypertension, etc.

Mortality increases to a mean age of 48.8 years, in which case this mortality is due to cardiovascular disease in $77 \%$ and $45 \%$ of these to heart failure ${ }^{10}$. Likewise, according to the severity of the disease, the most complex ones will die earlier, including patients with Fontan circulation, complex heart disease, Eisenmenger's syndrome, univentricular heart with right-sided systemic ventricle, and Ebstein's anomaly ${ }^{9}$.

Other studies show that the main causes of morbidity and mortality are heart failure in $28 \%$ and non-cardiovascular causes in $23 \%$, such as malignancy, pneumonia, liver failure, endocarditis and renal failure. $19 \%$ have sudden death, $18 \%$, other cardiac alterations such as coronary disease, diabetes, hypertension, obesity and stress, and 14\% vascular events, such as cerebral aneurysm and aortic aneurysm ${ }^{10}$.

Presence of pulmonary hypertension affects up to $6 \%$ of patients and has a very important impact on survival ${ }^{11}$.

\section{Neurological and psychological injuries}

The presencce of old neurological lesions and new events associated with metabolic alterations, significantly affect the independence of these patients. Likewise, it is predicted that up to $30 \%$ of these patients have psychological and psychiatric disorders, secondary to repetitive trauma, old experiences, as well as posttraumatic stress disorders $^{12}$

\section{Contraception and reproduction}

Contraception and counseling are very important as the incidence of children of these patients with congenital heart diseases is higher than that of the normal population; however, many of these patients have children and their mothers, specifically those with Eisenmenger Syndrome, Fontan surgery and cyanotic diseases may be at increased risk of complications such as arrhythmia, heart failure and cardiovascular events especially during pregnancy ${ }^{13}$.

\section{Prevalence of congenital heart disease in Colombia}

The prevalence of patients with congenital heart disease has stabilized in the world, and in Colombia, concretely it is of $9 / 1,000$ live births ${ }^{14,15}$. In the country according to DANE figures, 645,550 children are born each year, (year 2015) ${ }^{3}$ and with a prevalence of 9.1 / 1,000 live births it is assumed that 5,805 new children are born with congenital heart disease every year. Of these new patients, $70 \%$ (4,063 patients) require surgical or interventional treatment during the first year of life because the mortality without any treatment is high, almost $50 \%$. Unfortunately, only about 2,349 are intervened with surgery and 1,600 with interventional procedures (total of 3,949 ). Of these only 1,500 out of a total of 4,063 children under one year of age have an opportunity for medical management remaining approximately 2,500 new children without it and high mortality risk in this first year ${ }^{16}$. 
Patients with congenital heart disease who reach adulthood

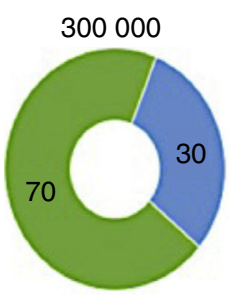

1965

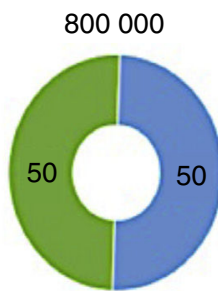

1985

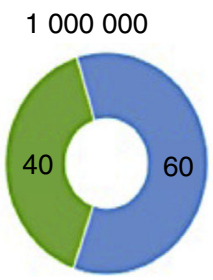

2005
1400000

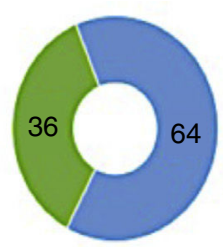

2015

Pediatric

Adults

Figure 2 Patients with congenital heart disease who reach adulthood

Relationship between adults and patients under 18 years with congenital heart disease through the years since the mid 1960 s when adults only accounted for $30 \%$ and 2015 when it is estimated to be $64 \%$. Williams et al.J Am coll cardiol 2006, Gilboa S circulation. 216; 134:101-109

\section{Prevalence of adults with congenital heart disease}

As mentioned above, the percentage of patients with congenital heart disease receiving treatment and surviving has improved significantly in the world and in Colombia, so a greater number of these patients reach adulthood. Another large number of individuals with less complex diseases will survive to adulthood and will only receive treatment after the age of 18 .

Prevalence studies for adults with congenital heart disease have been done as a systematic review and based on evidence calculations suggesting that the prevalence of adults with congenital heart disease in specific regions may be 3,000 per million inhabitants, ranging from 2,297 to 3,532 or 4.09 adults with congenital heart disease per 1,000 adults, according to epidemiological approaches based on Quebec population studies ${ }^{17,18}$. According to these approximations, it is estimated that the relationship between adults and children under 18 years of age with congenital heart disease has been reversed since the mid-60s, when adults only represented $30 \%$ and by 2015 would be greater than $64 \%^{2}$ (fig. 2).

\section{Adults with congenital heart disease in Colombia}

According to the approaches mentioned and if coverage and survival of newborns were similar to those of developed countries, in Colombia there would be 141,000 adults with congenital heart disease. However, due to deficiencies in early care of the newborn and deficiencies of the system, it is assumed that due to lack of efficiency in $60 \%$ of cases, only $40 \%$ will arrive to adulthood. We could speculate that we would only have approximately 46,000 adult patients with congenital heart disease.

\section{History and impact on treatment}

Cardiac surgery began in the early 1940s and 1950s with the ligation of the ductus arteriosus by Gross in Boston, the Blalock-Taussig shunt at John Hopkins Hospital in 1945, the repair of coarctation of the aorta in 1944 in Sweden by Crafford, and a large number of closed procedures. However, with the appearance of extracorporeal circulation introduced by Lillehey, Gibbon and Kirklin in the United States in the mid-1950s, a spectacular development was observed in intracardiac repair, which after the 1980s was successfully applied in the newborn and in the first months of age, changing the prognosis and survival of these patients.

Colombia, like Latin America, with the leadership of surgeons and cardiologists, was not an exception to this development and in 1948 the first ductus arteriosus closure was made; in 1952 Rueda performed possibly the first repair of aortic coarctation and later a group of national leaders in Bogotá and Medellin began intracardiac surgery using moderate surface hypothermia and cardiac arrest and later with the use of extracorporeal circulation, always supported by international pioneers such as Walton LIllehey, Melrose and Humprey, who visited Colombia and helped develop the different strategies of the moment.

Similarly, thanks to these pioneers and their disciples, schools and centers specialized in cardiovascular surgery were created, as well as training programs of this specialty, and for this reason, today patients with congenital heart disease in Colombia are more likely to survive and reach adulthood age ${ }^{19}$.

\section{Congenital heart disease centers for children and adults}

The main objectives for the care of these patients are based in the following factors: 


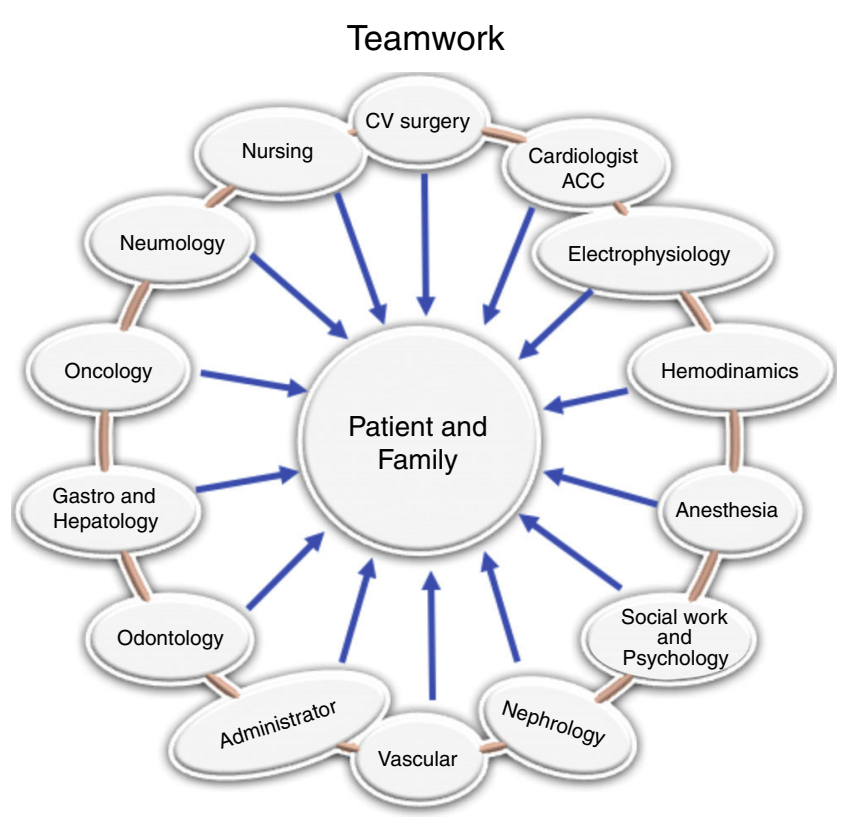

Figure 3 Congenital Heart Disease Center

Multidisciplinary group that must assume the integrated management of a center of adults with congenital heart disease.

1. The importance of maintaining care throughout their life.

2. The transfer of patients between their pediatric physicians to adult cardiologists with the least loss of follow-up.

3. The transition is a very important factor that includes a process of maturation in which the patient gains selfmanagement and achieves to create some independence from the care of his family. Others unfortunately do not succeed because of neurodevelopmental difficulties or psychosocial alterations secondary to the treatment process and its possible complications and comorbidities that they develop during their life.

Due to the constant growth of this population, centers specialized in congenital heart disease in adults have been created. These must include not only a specialist in adult congenital heart disease, but a multidisciplinary group for follow-up and management (fig. 3). Refer centers in general see between 2,500 and 3,000 patients per year and it is suggested that one center be created for every 2,850 patients, a fact that based on the projection of the number of adults with congenital heart disease in Colombia would merit having at least three specialized centers In this population.

The Cardioinfantil Foundation - Institute of Cardiology is a refer center in Colombia and Latin America. From 2005 to 2016, a total of 444 adults with congenital heart defects have been surgically intervened, most of them due to interatrial and interventricular defects, followed by reoperations in patients with previous repair of Tetralogy of Fallot, and partial venous drainage. Mortality in this group is low of $1.6 \%$, but the presence of arrhythmias is the most common in the postoperative period. Follow-up shows a survival of $97 \%(\mathrm{Cl} 95 \% 84-97)$ at 10 years $^{20}$.

\section{Conclusion}

The prevalence of adults with congenital heart disease is increasing and this population will be one of the great challenges of cardiology and cardiac surgery in the future.

It is critical to anticipate the changes of these patients over time and their comorbidities to minimize long-term complications.

The creation of centers of reference will be essential for proper management, transition and transference to guarantee a transitional and non-traumatic process for the patient and his family. In this sense, the work of a multidisciplinary team is crucial.

\section{References}

1. Moodle D. Adult congenital heart disease. Texas Heart Institute Journal. 2011;38:705-6.

2. Gilboa S, Devine OJ, Kucik JE, Oster ME, Riehle-Colarusso T, Nembhard WN, et al. Congenital heart defects in the United States Estimating the magnitude of the affected population 2010. Circulation. 2016;134:101-9.

3. Dane, Colombia. Proyecciones anuales de población por sexo y edad 1985-2015. Available at: www dane.gov.co

4. Khairy P, Ionescu-Ittu R, Mackie AS, Abrahamowicz M, Pilote L, Marelli AJ. Changing mortality in congenital heart disease. JACC. 2010;56:1149-57.

5. Warnes CA, Liberthson R, Danielson GK, Dore A, Harris L, Hoffman IE, et al. Task Force 1: The Changing Profile of Congenital Heart Disease in Adult Life. JACC. 2001;37:1161-98.

6. Jenkins JJ, Gauvreau K, Newburger JW, Spray TL, Moller JH, lezzoni LI. Consensus-based method for risk adjustment for surgery for congenital heart disease. J Thorac Cardiovasc Surg. 2002;123:110-8.

7. O'Brien SM, Clarke DR, Jacobs JP, Jacobs ML, Lacour-Gayet FG, Pizarro C, et al. An empirically based tool for analyzing mortality associated with congenital heart surgery. J Thorac Cardiovasc Surg. 2009;138:1139-53.

8. Hoffman JIE, Kaplan S. The incidence of congenital heart disease. J Am Coll Cardiol. 2002;39:1890-900.

9. Diller GP, Kempny A, Alonso-Gonzalez R, Swan L, Uebing A, Li W, et al. Survival prospects and circumstances of death in contemporary adult congenital heart disease patients under follow-up at a large tertiary centre. Circulation. 2015;132:2118-25. Available at: https://www.ncbi.nlm.nih.gov/pubmed/26369353

10. Verheugt CL, Uiterwaal C, van der Velde TE, Meijboom FJ, Pieper PG, van Dijk APJ, et al. Mortaliy in adult congenital heart disease. Eur Heart J. 2010;31:1220-9.

11. Lowe BS, Therrien J, Ionescu-Ittu R, Pilote L, Martucci G, Marelli AJ. Diagnosis of pulmonary hypertension in the congenital heart disease adult population impact on outcomes. J Am Coll Cardiol. 2011;58:538-46.

12. Linda B, Pauliks. Depression in adults with congenital heart disease-public health challenge in a rapidly expanding new patient population. World J Cardiol. 2013;5:186-95.

13. Drenthen W, Pieper PG, Roos-Hesselink JW, van Lottum WA, Voors AA, Mulder JM, et al., On behalf of the ZAHARA Investigators. Outcome of Pregnancy in Women With Congenital Heart Disease. A literature review. J Am Coll Cardiol. 2007;49:2303-11.

14. van der Linde D, Konings EEM, Slager MA, Witsenburg M, Helbing WA, Takkenberg J, et al. Birth prevalence of congenital heart disease worldwide. A Systematic review and meta-analysis. J Am Coll Cardiol. 2011;58:2241-7. 
15. Zarante I, Franco L, López C, Fernández N. Frecuencia de malformaciones congénitas, evaluación y pronóstico de 52.744 nacimientos de tres ciudades colombianas. MEDICA. 2010;30:65-71

16. Sandoval N, Kreutzer C, Jatene M, Di Sessa T, Novick W, Bernier $\mathrm{PL}$, et al. Pediatric cardiovascular surgery in South America: current status and regional differences. World J Pediat Congenital Heart Surg. 2010;1, 321.

17. van der BomT, Bouma BJ, Meijboom FJ, Zwinderman AH, Mulder BJM. The prevalence of adult congenital heart disease, results from a systematic review and evidence based calculation. Am Heart J. 2012;164:568-75.
18. Marelli AJ, Therrien J, Mackie AS, Ionescu-Ittu R, Pilote L. Planning the specialized care of adult congenital heart disease patients: from numbers to guidelines; an epidemiologic approach. Am Heart J. 2009;157:1-8.

19. Laverde A. La cirugía cardiovasvular en Colombia. Rev Colomb Cardiol. 1985;1.

20. Sandoval N. Status and challenges of care for adults with congenital heart disease in Latin America. $5^{\text {th }}$. Scientific meeting WSPCHS Adu Dhabi. UAE Submitted WJPCHS. 2016. 